\title{
The role of information and communication technology in building management system
}

\author{
Elham Fariborzi ${ }^{1, ~ *, ~ G o l n a z ~ T a v a s s o l i a n ~}{ }^{2}$ \\ ${ }^{1}$ Department of Educational Sciences, Mashhad branch, Islamic Azad University, Mashhad, Iran \\ ${ }^{2}$ Department of Architecture, Mashhad branch, Islamic Azad University, Mashhad, Iran
}

Email address:

elhamfariborzi@gmail.com (E. Fariborzi),golnaz.tavassolian@gmail.com (G. Tavassolian)

\section{To cite this article:}

ElhamFariborzi, GolnazTavassolian. The Role of Information and Communication Technology in Building Management System. International Journal of Science, Technology and Society. Special Issue: Research and Practice in Architecture and Urban Studies in Developing Countries.Vol. 3, No.2-1, 2015, pp.1-4.doi: 10.11648/j.ijsts.s.2015030201.11

\begin{abstract}
Nowadays, Information and Communication Technology (ICT), as the main axis of transformation and development in the world have incorporated achievements that neglecting them makes a chaos in the society and well-being of people. Key role of novel information and communication technologies in various fields cannot be ignored. Smart houses are important components of country's development plan and also thorough building management systems and technologies. The purpose of this article is to study the role of information technology and communication in making buildings intelligent from different angles. This would cause peace, silence and additional security along with optimizing energy usage, as well as saving time and money in building maintenance.
\end{abstract}

Keywords: Information and Communication Technology, BMS

\section{Introduction}

New technology in most professions like building management system has provided a suitable situation to gain advancement and development of quality inside human life. Technology as an engine for society leads to development, growth, and flourish of its different parts. Hence, considering information and communication technology in developing plans plays an essential role. In today's world, human society communications are affected by urban development, a phenomenon having world traits and a special aspect in modern civilization [1]. City as the origin for human civilization has always been under attention of theorists of different sciences. The most important traits of our time are urbanism of population, increase in cities' populations and consequently development of small and big cities [2]. Quick growth of population and their focus in cities worldwide affects prospects of life of most humanity. Undoubtedly, achieving smart technologies plays an important role in enhancing citizen's lives. With the increase in city population, we need new cities to be built equipped with the latest technologies. Today, making intelligent as a unique solution for solving urban issues has been the focus of attention of urban planners and city managers. Of new technologies in housing and usages of advancement of technology, we can point to intelligent and management of energy saving in buildings. Increasing usage of energy, its resource finite-ness, and undesirable and irrecoverable effects of uncontrolled energy consumption on environment on one side and recent increase in its price on the other side have made consumers and administrators of energy to find ways for saving energy. Usage of buildings technologies not only decreased usage of energy but also provided appropriate and ideal conditions and increased welfare of inhabitants [3].

In building technology, along with applying appropriate design methods to minimize materials and maximize efficiency, building materials are used to minimize energy consumption in production. Therefore, recyclable materials are used to be reused after their efficient lifetime is over [4]. Building management system (BMS) is a collection of software and hardware to seamlessly monitor and lead an important and vital part of a building. Task of this collection is constant monitoring of different parts of building and leading in way which performance of different parts of building together is efficient, undesirable usages decrease and pleasant and safe environment is created [5]. Information and communication technology provides this needed infrastructure to immediately exchange information in long 
distances. For this reason, the main aim of this article is studying different aspects of information technology in developing plans in line with making buildings intelligent. Due to the role of information technology in building approaches, it is essential that Practitioners of housing sector including Organization of Housing and Urban Development vividlylook at this section of technology.

\section{Theoretical Principles of the Research}

The challenges facing developed countriesarepreparation of society and government for globalization and a revolution in IT and Technology [6]. In this research, based on gathered data from literature review it has been attempted to provide a suggestion through explanatory and descriptive method assess of gathered data. We have studied relevantliterature sources and research history conduct arguments like information and communication, building management, Fifth Development Plan policies and building technologies. Records show that in proportion to existing and developing infrastructures, different countries have attempted to construct the smart city in a way to be able to utilize facilities in IT field.

\section{Information and Communication Technology (ICT) in Building Management System}

Nowadays, when we talk about technology different machines, computers, big buildings, media, and other tools in industry and their effective role in economics and culture of society come to our mind. It is natural that these tools are those achievements of technology satisfying all basic needs of contemporary man [7]. Technology of doing work is at all levels and designing, production, usage, maintenance, repair, research and development fields. In international Webster dictionary in 1909 technology was defined with the meaning of industrial science, systematic knowledge or science of industrial arts especially for important productions while in 1961 technology was technology as a collection of tools used by people to present their aims, considering materials. In seventh edition of this dictionary, technology is defined as a technical tool to achieve scientific goals [8]. Technology is the process of transferring and converting resources to products, knowledge, experience, information and tools [9]. Daniel Bel in the future of technology book, knows technology as the only tool to remove limitations and facilitate tasks [10]. Information technology is a technology thatemployscomputers to gather, process, store, protect, and transfer information [11].Information Technology focuses on activities that deal with the solution of problems through logical thinking, information management and communication. It also focuses on the development of computer applications using current development tools [12].

ICT provides required infrastructures to quickly exchange information in long distances.Information technology is not the cause of the changes we are living through. However, without new information and communication technologies none of what is changing our lives would be possible [13].

\section{Building Technology and Building Management System}

Building technology has an effective role in creating a suitable environment as well asin increasing safety and security in buildings. In fact, building technologies have a crucial role in facilitating building management through an integrated system of infrastructures, a logical relationship between emergency electricity distribution system, system for receiving information about consumption rate and performance of different parts of the building to decide appropriately, capability of changing the method of energy and facility distribution in specific times and critical situations. Making intelligent is one of the appropriate ways of optimizing energy consumption and durability in buildings.

Integrated and smart management system of building (BMS) is a collection of hardware and software to seamlessly monitor and lead vital and important parts of buildings. This system makes management and control of building status possible through automatic light, traffic (entrances and exits), heating and cooling, alarm and fighting fire, and powerhouse control.

Implementing BMS in buildings mostly is pursued by the following purposes:

- Optimizing and saving energy consumption

- Providing an appropriate environment for inhabitants of the building

- Consistent monitor of all building compartments

- Building management at the time of a disaster

- Decrease in maintenance expenses

- Optimized usage of equipment and elevating their efficient lifetime leading to building durability

- Exact statistical reporting of performance of each separate building part to optimize consumption and performance and exact exploitation record of different parts of building.

- Smart prioritizing of consumption in disaster [14]

In the following items, instances of using intelligent system facilities are provided:

- Remote Control:you can control all systems with the created image via cell phone or internet.

- Light control: smart system of lighting makes possible to control electronic energy and supply appropriate light. Logic for this control is defined based on the needed light intensity and the space. One of the advantages of implementing smart system in buildings is that in every condition, which the logic of control is changed, you can implement the new logic just by applying in plans without the smallest physical change. Different modes of lighting in situations like party, night, trip, and outside the building for personal buildings; and conditions like holding a meeting, lecture, movie, 
reading, and using the computer for official buildings; is definable. Of other advantages of implementing smart lightening system, we can point to time-based planning, light control through automatic voltage reduction (Dimmer), controlling keys via remote controls, light control based on the light intensity of the environment, avoiding energy dissipation and removing unwanted usages.

- Temperature control: in a smart system, environment temperature is exactly calculated and is set through a controllable valve based on the predefined logic. This control valve can automatically be closed as windows are opened.

- Safety and security control: in this system, security control function, manage all signals dependent of security devices and consequently set the danger signals [15].

- Simulating residents' presence: during the absence of residents, windows naturally open and close, lamps, and media are turned on and off exactly like when individuals do at their presence to stop burglars knowing the building is empty.

- Situation of Locks: at the time of doors and windows being closed, all the contacts are checked. In case not properly closed, alarm starts warning.

- Intruder disposal: if windows or doors are opened by force, security system becomes activated and motion sensors detect presence of illegible individuals. If residents are present and feel a danger, can activate the whole security system just by pressing a button.

- System of canopies and curtains: canopies and curtains can be controlled based on the logic and based on the conditions. You can use all the curtains and canopies automatically or through a remote control to change the lightening of rooms. Related controlling function can act fully automatic or based on the predefined time, or based on the level of lightening and wind change. For example, all windows can be closed after six, or if lightening goes down lower than needed or if windows are open and a heavy wind start blowing, to avoid possible damages, windows become closed.

- Early warning systems: alarm system can be activated at the same time as light system and activate quiet and telephone warning. Quiet alarms notify neighbors, emergency services or police via telephone line.

- Alarming and extinguishing fire: smoke or heat sensors are set with electronic systems inside the building. In fact, internal systems like connected chains are planned against possible dangers and in addition to that security is applied in an appropriate time which harms haven't' damaged the building yet [16].

- Technical alarms: smart building manages technical messages. Therefore, residents become aware of damages to water or electric circuits beforehand and prevent upcoming issues.

Through stable architectural design and applying new technologies in construction, we can achieve sustainability in design and construction. Most of advancements and new technologies in designing and construction have been toward sustainability and enhancement of architectural spaces. Of smart buildings, we can point to Z6 in Santa Monika, Canada and Sidle Friends Middle educational building.

Through building model information (BIM), buildings according to human needs can be built [17]. Building model information is software that provides the ability to design perfect buildings with all details. This software also provides the function of 3D and exact designing of buildings [18]. BIM allows contractors to plan implementation method and materials before splitting the project field and architects use it to exchange information among them.

\section{Developing Countries Plans in line with Management Systems}

In recent years, planning in big and complex organizations is leading to hierarchy structure because this structure type is able in according changes. Hierarchy of policies provides this possibility to select policies in every level separately, in a way that in level one subjects and policies are reviewed comprehensively and finally as operative and applicable in lower levels. Iranian organizations are not an exception. Peter Hall knows planning as a management for complex systems [19]. It is essential to conduct integrated planning and management system of implementing the plan to coordinate among different parts of structural-strategic design; breaking planning process into two strategic and operational levels and mixture of planning elements with administrators and public participation, executive organizations and professional planning institutions to expand the urban development project [20].

Since technology in country's development plans is one of the considered subjects, we point to some of them in economic, social and cultural Fifth Development Plan of Islamic Republic of Iran [21]:

1 Efficient use of information and communication technology to realize cultural purposes

2 Enabling private sector to participate in science and technology creations

3 Access to advanced needed technologies

4 Giving identity to the appearance of city and village, recreation and update of Islamic-Iranian architecture, observance of advanced criteria for safety of buildings and constructions strength

5 The overall strategy of region development and considering cumulative effects of these strategies

6 Index of development effects in environment and biological capacity index

7 Applying regional and national sustainability indexes

8 Empowerment programs and determination of the mechanism of executive assessment for environmental strategies

9 National conduction of sustainability indexes

10 Creating database and information about sustainability 
indexes

11 Determining sustainability indexes and quantifying them for the planned years

12 Determining sustainability criteria supervising environmental load balancing and controlling development effects over natural and human environment.

Considering mentioned policies and emphasizing 3, 4, and 7 , necessity of making buildings intelligent becomes evident.

\section{Discussion and Conclusion}

Like live creatures, cities are all the time under change, expansion and development. As the world is walking toward electrifying, citizens also need to join this stream to continue social, political, and economical life. This is facilitated through information and communication technology. Therefore, applying information and communication technology in buildings cause efficient use of buildings, decrease in energy consumption of buildings, and consequently sustainable buildings. As mentioned in country's Fifth Development Plan, access to advanced needed technology, observance of advanced criteria for safety of buildings and construction strength, and applying regional and national sustainability indexes must be operationalized. Thus, making intelligent by the use of building model information in design and construction stages, it becomes possible to build perfect, sustainable and hale buildings. As in Islamic Republic of Iran's Fifth Development Plan, use of new technologies has been emphasized, in buildings information and communication technology must be used in designing and construction stages.

\section{References}

[1] S. Mahalati, "Human, social, environmental,"ShahidBeheshti University Press, Tehran, 1998

[2] A. Kiani, "Smart City, the necessity of the third millennium, the integrated commerce interactions (conceptual-performance models with an emphasis on cities)," 2011

[3] A. Vafaee, E. Poorestekanchi, and Q. Qadimi, "Role of information technology in the construction sector," Iranian Journal of Engineering Education,Vol1, No 4, 1999

[4] M. Khatami, M. Falah, "Role of sustainability in architecture and building," Iranian Journal of Sofeh, Vol 20, No 50, 2010
[5] Z. ghanad, "Intelligent Building Systems," Project Management Support Office, 2009

[6] L. Tinio, "ICT in Education," United Nations Development Program, Bureau for Development Policy,2002

[7] F. Basiti, "Examine the effects of technology on human health and environment and architecture," City and Landscape Magazine, Vol. 3, No. 29, 2013

[8] M. Heidegger, "The Question Concerning Technology," Translator R. Asadi, AndishehInstitute, Tehran, 1995

[9] E. Mohammadzadeh, "Future management by the technology of tomorrow," Iziran Institute, Tehran, 2001

[10] B. Daniel, "future technology," translated by A. alyqiyan, Publications Center of the Ministry of Foreign Affairs, Tehran, 2003

[11] V. Kuo, "ITdesk.info - project of computer e-education with open access (Basic Concepts of Information and Communication Technology)," Open Society for Idea Exchange (ODRAZI), Zagreb, 2011

[12] "Information Technology," Republic of South Africa, Department of Education, National Curriculum Statement

[13] M. Castells, "Information Technology, Globalizationand Social Development," UNRISD Discussion Paper No. 114, September 1999

[14] A. Janbozorgi, "Intelligent Building Systems," Journal of Caisson, No. 43, 2009

[15] P. Badaqi, A. Abedi, "Building Management System," Publication of DaneshNama,No 165, 2010

[16] H. Myrqany, K. Hosni, "Building Management Systems," Third Conference of the National Building Regulations, Iran, Mashhad, 2010

[17] S. Jones, M. Hill, "Building Information Modeling (Understanding and Operating in a New Paradigm)," Foundation of the Wall and Ceiling Industry, 2009

[18] L. Sabol, "Building Information Modeling \& Facility Management," IFMA World workplace, 2008

[19] H. Peter, "Urban and Regional planning," translated by J. Tabrizi, publication, processing and urban planning, 2002

[20] N. Barati, M. Barati, "Understanding urban development projects in Iran," Publications of municipalities and villages in the country, Tehran, 2011

[21] "Fifth Five-Year Development Plan of the Islamic Republic of Iran,"Publications of Vice President Strategic Planning and Monitoring,2009 